\title{
Accessory Mental Foramen of the Mandible Found With Radiographic Images: A Case Report
}

\author{
Kabir $\mathrm{H}^{1}$, Mallick $\mathrm{PC}^{2}$, Sarwar AFMํ, Rizvi $\mathrm{HM}^{4}$
}

\begin{abstract}
The object of this study is to present a case of an accessory mental foramen. Detection of the position of mental foramen is important during surgical procedures in terms of achieving effective mandibular nerve blocks and avoiding injuries to the neurovascular bundles. A 64-year-old man visited us for taking treatment. Preoperative panoramic radiography and CT were conducted. A multi-section reconstructed sagittal image showed two mental foramina leading to the mandibular canal on the right side of the mandible, which were considered to be double mental foramina. Although no surgical procedure was planned, the patient was informed about the existence and importance of the anatomical variation with regard to the need for local anesthesia, diagnosis of periapical diseases, and the prevention of nerve damage during surgery in that area of his mandible.[J Shaheed Suhrawardy Med Coll, 2014;6(2):90-92]
\end{abstract}

Key Words: Accessory mental foramen, mandible, radiographic images

Received: July 2014; Revised: October 2014; Accepted: November 2014

\section{Introduction}

The mental foramen is an opening on the lateral parts of the body of the mandible, inferior to the premolars region, through which passes the mental nerve and blood vessels ${ }^{1-3}$. Usually, single mental foramen is present in one side of each mandible ${ }^{1-3}$. However, multiple mental foramina in human mandible is also reported ${ }^{4-6}$. Mental foramen is an important anatomical structure of particular importance in local anesthesia and surgical procedures in terms of achieving effective mandibular nerve blocks, avoiding injuries to the neurovascular bundles and strategically important landmark during osteotomy procedures ${ }^{7-10}$. Surgical correction of jaws and facial deformities, treatment of fractures and pathological lesions within the jaw bones and facial structures have becomes common procedures in Bangladesh. Placement of implants in these jaws is also becoming popular to this country. Before these procedures practitioners should very concerned about the position of the mandibular canal, especially its route near the mental foramen to avoid unwanted injuries to these mental nerve and vessels. The possibility that an anterior loop of the mental nerve may be present mesial to the mental foramen needs to be considered before implant surgery to avoid mental nerve injury ${ }^{7-8}$. The foramen may appear on conventional radiographs like panoramic images and periapical radiographs. However, computerized tomography (CT) scans are more accurate for detecting the mental foramen man conventional radiographs. The mental foramen is usually single in each side of mandible and may be oval or round in shape and is usually located apical to the second mandibular premolar or between apices of the premolars. However, its location can vary from the mandibular canine to the first molar ${ }^{1-4}$, and the common position of mental foramen of the population of each country is different from those of other countries. Though, most of the improved countries have already established a result about the position of the mental foramen on the mandible of their population. However, we are working to establish a data to identify the common position of mental foramen on the mandible in the population of Bangladesh. Subsequently, we found a patient who has double mental foramen in one side of his mandible. Although rare, multiple mental foramina have been described in human mandibles. In these cases one foramen is termed the mental foramen and the others are referred to as an accessory mental foramen.

\section{Presentation}

A 64-year-old man came to us with a complaint of mild pain at the area of his right mandibular molar region. Clinically, we found moderate mucosal inflammation at his right edentulous mandibular region. In addition to clinical

1. Dr. Md. Humayun Kabir, Associate Professor and Head, Dental Unit, Shaheed Shurawardy Medical College, Dhaka

2. Dr. Parimal Chandra Mallick, Associate Professor and Head, Department of Dental Radiology, Dhaka Dental College \& Hospital, Dhaka

3. Dr. A.F.M. Sarwar, Assistant Professor, Department of Children, Preventive \& Community Dentistry

Shaheed Shurawardy Medical College, Dhaka

4. Dr. Hasan Mohammad Rizvi, Lecturer, Department of Orthodontics, Dental Unit, Shaheed Shurawardy Medical College, Dhaka

\section{Correspondence}

Dr. Md. Md. Humayun Kabir, Associate Professor and Head, Dental Unit, Shaheed Shurawardy Medical College, Dhaka, Bangladesh; Email: drhumayunbulbul@gmail.com 
examination, we advised the patient for radiographic examinations. Panoramic radiographic image showed a well defined radiolucency at the area around the apical region of his loosed right mandibular premolar teeth (Fig.1). This radiolucent area is defined as the mental foramen at the right side of mandible. The other radiolucency was found distal to this right mental foramen which was preliminary suspected as an accessory mental foramen. For further confirmation, computed tomography (CT) scans were carried out. The axial view of CT scans of the mandible showed two recesses in the buccal cortical bone of the right body of the mandible. The anterior recess is defined as the mental foramen and the second recess immediately posterior to the mental foramen is to be referred as the presence of an accessory mental foramen (Fig. 2). A reconstructed sagittal image also showed two opening those have an obvious continuation to the mandibular canal (Fig.3). These findings are confirming that the distal smaller opening is the accessory mental foramen.

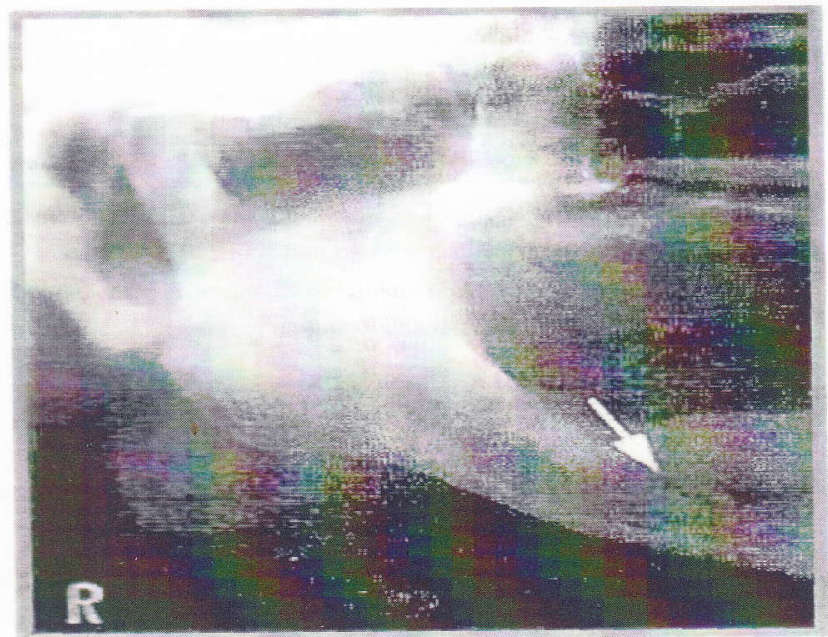

Fig. 1. Cropped panoramic view of a 64-year-old man shows the mental foramen as a well-defined radiolucency around the apical region of the mandibular right premolars. An additional radiolucency was found distal to this mental foramen (white arrow).

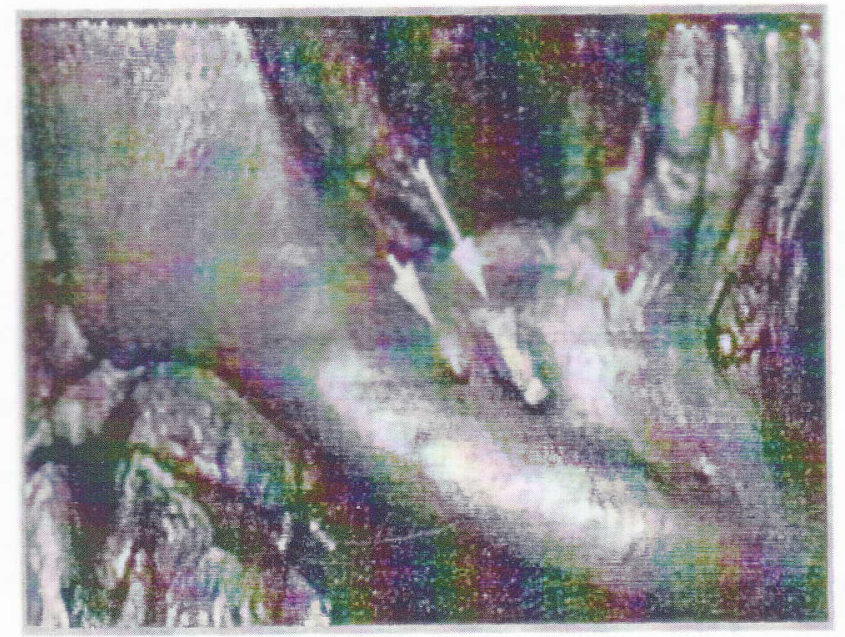

Fig 2. Reconstructed three-dimensional computed tomography (CT) image shows two small foramina on the right side of the mandible (white arrow)

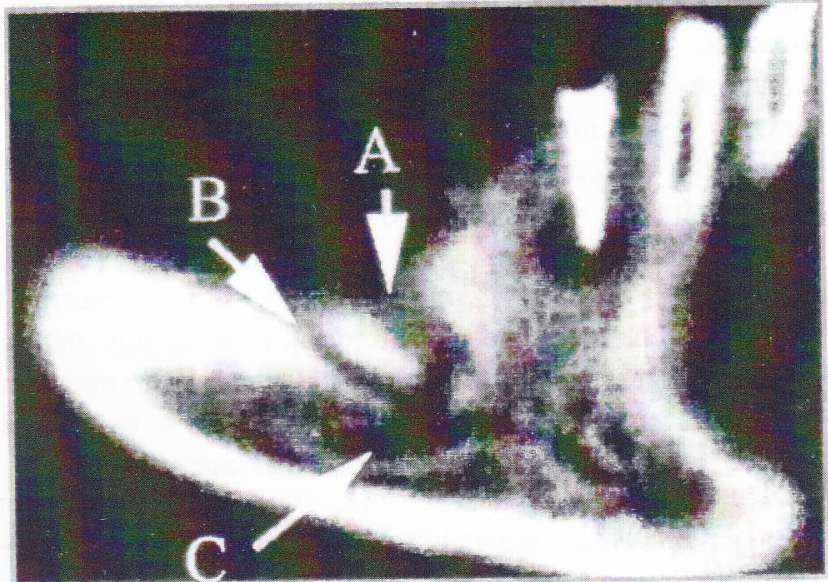

Fig. 3. Reconstructed sagaittal image of the right mandible shows two opening of the mandibular canal towards the alveolar ridge. Arrow 'A' indicates the mental foramen, ' $\mathrm{B}$ ' indicates the Accessory mental foramen and ' $\mathrm{C}$ ' indicates the mandibular canal.

Table 1: Incidence of multiple dental foramina in human mandible reported by many researchers in the world ${ }^{12}$ :

\begin{tabular}{lllr}
\hline Publication year & Researchers & Population & Incidence (\%) \\
\hline 1860 & Nogawa and Aratani & Japan & $7.4 \%$ \\
1872 & Gruber & Russian & $2.9 \%$ \\
1892 & Bertelli & Italian & $5.5 \%$ \\
1906 & Le Double & French & $5.3 \%$ \\
1923 & Simonton & Negro & $16.6 \%$ \\
& & Melanesian & $10.3 \%$ \\
& & Eskimos & $8.7 \%$ \\
& & White & $6.5 \%$ \\
& & Kentuccky Indian & $5.3 \%$ \\
& & Arkansas Indian & $4.6 \%$ \\
& & California Indian & $2.3 \%$ \\
1927 & Hori & Kanazawa, Japan & $7.6 \%$
\end{tabular}

1954

1973

1989

1992

2002

\begin{tabular}{lll} 
Montagu & Central European & $5.3 \%$ \\
Sekiguchi and Sato & Kanto, Japan & $5.0 \%$ \\
Zografos and Mutsuri & Greek & $6.7 \%$ \\
Mwanik and Hassanali & African & $8.8 \%$ \\
Kieser et al. & Caucasoid & $2.7 \%$ \\
& Negro & $7.6 \%$ \\
& Maori & $9.0 \%$ \\
\hline
\end{tabular}

\section{Discussion}

In general, a human mandible contains mental foramen on its both sides. The location of these mental foramen on the mandible varies from the mandibular canine to the first molar $^{1-11}$, and the common position of mental foramen of the population of each nation is different from those of other countries ${ }^{12}$. Most of the improved countries have already established a result about the position of the mental foramen of their population ${ }^{12}$. In our country, oral and maxillofacial surgery has become very common surgical procedures and simultaneously, dental implant is also becoming a popular surgical procedure. Before performing any of these procedures, it is very important to have 
sufficient knowledge about the position of this mental foramen. In this concept, we are working to publish a guideline about the common position of this mental foramen on the mandible in the population of Bangladesh. During the collection of different radiographic data from several patients, we have found a case among 120 patients having double mental foramina on right side of his mandible. Previously, some authors have described multiple mental foramen as abnormalities of the mental foramen, including bisectional or trisectional foramina, in which the foramen is partitioned by one or two bone trabeculae. and plural foramina some distance apart ${ }^{4-6}$.

In this case report, the foramina were suspected separate because a nonseptum, cortical bonelike structure was observed on the reconstructed image. On the basis of published articles, the main foramen is clearly distinguishable by size and shape from the smaller subforamen $^{9-11}$. Accordingly, we considered the larger foramen as the main foramen and the smaller posterior foramen to be the subforamen. Though, a human has a pair of mental foramina, a single foramen on either side of each mandible. However, more than one or an absence of foramen has also been established ${ }^{4-6}$. Some authors have reported in details the incidence of multiple mental foramina (table 1$)^{12}$. Our study has also found the double mental foramen in one patient, similar to several well known published results in the population of other countries. Moreover, we have to collect further data for to establish the common position of this mental foramen and the incidence of double mental foramen on the mandible in the population of our country.

\section{References}

Simonton FV. Mental foramen in the anthropoids and in man. Am J Phys Anthropol 1923; 6: 413-21.

2. Mwaniki DL, Hassanali J. The position of mandibular and mental foramina in Kenyan African mandibles. East Afr MedJ 1992; 69: 210-213

3. Montagu MFA. The direction and position of the mental foramen in the great apes and man. Am J Phys Anthropol 1954; 12: 503-18.

4. Zeze R, Kagawa T, Ogawa K, Mori S. Double mandibular canals: report of a case. Oral Radiol 1996; 12: 33-37.

5. Riesenfeld A. Multiple infraorbital ethmoidal, and mental foramina in the races of man. Am J Phys Anthropol 1956; 14: 85-100.

6. Toh H, Kodama J, Tsuno K, Yanagisako M, Yamada M, Kim K. et al. Accessory mental foramen and its nerve in a Japanese male. J Fukuoka Dent Coil 1992; 19: 452-456.

7. Cocepcion M, Rankow HJI. Accessory branch of the mental nerve. J Endod 2000: 26: 610-620.

8. Hanihara T. Ishida H. Frequency variations of discrete cranial traits in major human populations. IV. Vessel and nerve related variations. JAnat 2001; 199:273-287.

9. De Fresas V, Madeira MC, Toledo Filho JL, Chagas CF. Absence of the mental foramen in dry human mandibles. ActaAnat 1979; 104: 353-355

10. Gershenson H, Nathan H, Luchansky E. Mental foramen and mental nerve: changes with age. ActaAnat 1986; 126: 21-28

11. Kieser J, Kuzmanovic D, Payne A, Dennison J, Herbison P. Patterns of emergence of the human mental nerve. Arch oral Biol 2002; 47: 743-747

12. Chinami I, Kaoru K, Akira Y, Yasuhiko M, Mamoru T. Double mental foramina of the mandible on computed tomography images; a case report. Oral Radiol 2004; 20: 68-71 